\title{
Nietzsche como psicólogo e o problema da consciência
}

\author{
Nietzsche as psychologist and the problem of consciousness
}

\author{
Yan Menezes Oliveira; Fabio Hebert da Silva
}

Universidade Federal do Espírito Santo

\section{RESUMO:}

O artigo visa apresentar a proposta de psicologia de Nietzsche e sua relação com seu método crítico de análise genealógica. Para a elucidação desta psicologia, bem como exemplo de seu funcionamento, apresentou-se as interpretações genealógicas de Nietzsche sobre a formação histórica da concepção moderna da alma e da emergência do aparelho da consciência. Trabalhou-se a concepção da "grande psicologia" como ferramenta do método crítico genealógico que busca se distanciar dos preconceitos morais metafísicos, como "atomismo anímico", centralidade do "eu" e do órgão da consciência no campo da existência humana, e o conceito de "livre-arbítrio". Através da eleição do corpo e da "grande razão" como alicerces da existência, a psicologia nietzschiana poderia realizar análises genealógicas do órgão da consciência baseando-se na construção do humano a partir da formação de comunidades, da produção de comunicação entre seus pares, e da limitação desta comunicação por parte da malha gramatical que determinaria sua perspectiva.

Palavras-chave: Nietzsche, Psicologia, Genealogia, Consciência

\begin{abstract}
:
The article aims to present Nietzsche's psychology proposal and its relationship with his genealogical analysis critical method. To elucidate this psychology, as well as an example of its functioning, Nietzsche's genealogical interpretations about the historical formation of the modern conception of the soul and the emergence of the consciousness apparatus were presented. The conception of "great psychology" was worked on as a tool of the genealogical critical method that seeks to distance itself from metaphysical moral prejudices, such as "soul atomism", centrality of the "I" and the organ of consciousness in the field of human existence, and the concept "free will". Through the choice of the body and "great reason" as the foundations of existence, Nietzschean psychology could carry out genealogical analyzes of the organ of consciousness based on the construction of the human from the formation of communities, the production of communication between peers, and the limitation of this communication by the snares of grammar that would determine his perspective.
\end{abstract}

Key-words: Nietzsche, Psychology, Genealogy, Consciousness

DOI: 10.12957/mnemosine.2021.61841

\section{Introdução: Nietzsche como psicólogo}

Quando Friedrich Nietzsche indaga-se em seu livro Ecce homo, escrito em 1888, 
se haveria antes dele algum psicólogo entre os filósofos (EH, Por que sou um destino, $\S 6$ ), podemos enxergar ao menos três motivos para tal. O primeiro motivo, diria respeito à manutenção de uma crítica genealógica a respeito da própria formulação do conhecimento a respeito da psicologia. Segundo o autor (ABM, §23), a psicologia tradicional, diferentemente da "fisio-psicologia" que este propõe, não avançaria por conta da força dos preconceitos morais, isto é, hábitos de perspectiva, valores estagnados e tidos como já dados na discussão acerca da alma e da existência. São exemplos desses preconceitos morais o "atomismo anímico" e a primazia dos impulsos e valores tidos como "bons" sobre os tidos como "maus" para o desenvolvimento do ser. Sua psicologia teria como projeto, portanto, movimentar-se sem depender desses preconceitos morais metafísicos e sempre com sua atenção voltada à certa dimensão de produção ou invenção, tanto dos valores morais quanto do próprio real.

Como segundo motivo, que diria respeito à tarefa negativa da psicologia proposta pelo filósofo, pode-se apontar a tentativa de dissociar tal ciência da consciência como principal objeto de estudo. Mais ainda, a psicologia de Nietzsche visaria demolir a concepção, vigente ao longo da modernidade, de que o ego e a consciência seriam os fundamentos do espírito e que o próprio universo teria sua constituição e dinâmica relacionada de algum modo a esses fundamentos. Oswaldo Giacoia Jr. (2001) na obra em que discute a importância de Nietzsche como psicólogo, ressalta que a psicologia da época em que Nietzsche escrevia, se basearia quase que exclusivamente no problema da consciência, seja ela representada pela discussão filosófica da alma, seja ela representada pela nascente psicologia científica.

Por fim, o terceiro motivo aqui destacado se localizaria dentro da segunda tarefa de sua psicologia, inserido em seu aspecto positivo, propositivo. Nietzsche (Z, I, Dos desprezadores do corpo) traz o corpo como a "Grande Razão" que orientaria o ser e a qual a “pequena razão", vinculada à consciência e à forma de existência humana, seria submissa. Ou seja, haveria na psicologia de Nietzsche uma inversão de valores da tradição filosófica ocidental moderna que tende a colocar as ideias e a mente em um nível superior em relação às sensações e ao corpo. Mais do que mudar o que deveria ser compreendido como o centro da psicologia, corpo sobre mente, Nietzsche (ABM, §19) aponta o corpo e as suas vontades como pluralidades, um conjunto de parcialidades e impulsos ao invés de uma organização psíquica centralizadora.

Ao mesmo tempo, a psicologia como apresentada por Nietzsche, principalmente no aforismo 23 de Além do bem e do mal, rebateria os preconceitos morais metafísicos 
presentes no pensamento da modernidade que defendem a unidade subjetiva e a existência de valores e atitudes boas e más em si, sendo que, na tradição moral de seu tempo, essas características corresponderiam ao altruísmo e ao egoísmo, respectivamente. Em lugar da distinção comparativa da lógica moderna, que dividiria os impulsos entre "bons" e "maus" por natureza, Nietzsche irá propor o conceito de "vontade de poder" como impulso básico que moveria os corpos do Universo, bem como a vida e a existência. Seria sobre esse impulso básico não dualista, sobre a "vontade de poder" (vontade que impeliria, no caso da existência humana, a uma interpretação e uma avaliação o mundo a partir de sua própria perspectiva), sobre a trajetória e a morfologia deste impulso que a psicologia nietzschiana se debruçará. Tem-se aqui, um princípio fundamental ("vontade de poder"), que concebe um real, um mundo, e, portanto, uma noção de humano, que pode prescindir de uma causa externa, que pode ser afirmado como causa de si.

A esta psicologia para além dos valores morais metafísicos da tradição de uma época específica, engrandecida pelo autor ( $\mathrm{EH}$, Por que sou um destino, §6) chamaremos no presente trabalho de "grande psicologia". Uma tal psicologia que navegue de maneira crítica em relação aos valores morais, segundo Giacoia (2001), faria parte do projeto de filosofia genealógica de Nietzsche. Tal projeto implica um diagnóstico crítico, uma genealogia dos valores e das interpretações tomados como naturais, sejam estes produzidas por um povo, um indivíduo, um sistema de pensamento, etc. Seria através da pesquisa genealógica que o filósofo vestindo a máscara do psicólogo, ou do médico, seria capaz de diagnosticar os "indivíduos", os sistemas de pensamento, os modos de existência e a cultura.

\section{A psicologia e o método genealógico}

O método crítico genealógico proposto e elaborado por Nietzsche ao longo de sua obra é sucintamente apresentado no prefácio de Genealogia da moral. Em resumo (GM, Prefácio, §2) seria um método de pensamento e pesquisa para se desdobrar a origem dos preconceitos morais e a das valorações, aparentemente estáticas, tanto de "bem" e de "mal", quanto como de "bom" e de "ruim", dentro de determinados sistemas filosóficos ou morais, ou modos de existir de um indivíduo, de um povo ou de uma época. Abrindo mão de uma suposta realidade última por trás ou além deste mundo, a genealogia buscaria, de maneira imanente, encontrar a gênese dos valores que constituem os julgamentos e interpretações morais, baseando-se na transformação da vontade de poder, vontade esta que seria capaz de produzir valores e sentidos para o mundo (ABM, §23; Z, II, Da 
redenção). Em outras palavras, a pesquisa genealógica proporia uma história crítica da constituição da moral, documentada e comparativa entre os costumes de diferentes culturas e modos de vida. Dessa forma, Nietzsche passa a avaliar o valor dos próprios “valores" (GM, Prefácio, §6).

A partir da perspectiva genealógica, toda moral seria tida como sintoma, como signo e expressão da transformação da "vontade de poder”. O psicólogo genealogista acompanharia historicamente a mutação da "vontade de poder", podendo avaliá-la como miserável e degenerescente, quando esta se volta contra a própria vida, o mundo material e a realidade, ou como promotora do crescimento e da superação do ser humano quando esta promove os instintos de vida. Pode-se entender, a partir do aforismo 23 de Além do bem e do mal, que a responsável pela avaliação da transformação histórica da "vontade de poder", a condutora deste método genealógico, seria essa psicologia concebida por Nietzsche.

Ainda em relação ao aforismo 23 de Além do bem e do mal, seria essa psicologia a rainha das outras ciências, aquela que levaria aos problemas fundamentais, isto é, os problemas da origem dos valores e sentidos que se apresentam como dados, cristalizados e resistentes à problematização no presente, ou seja, seria essa a ciência que, ao compreender toda produção de conhecimento como algo encarnado, como expressão dos impulsos daquele que os expressa ( $\mathrm{ABM}, \S 6)$, renovaria o estudo do próprio conhecimento e de sua produção de valor e sentido. Seria a ciência capaz de alcançar o problema da composição de forças, inclusive da composição de forças que se apresentam como causas primeiras e imutáveis, causas independentes da história e sem procedência. Seria a "grande psicologia" que conseguiria estudar a transformação de um valor ideal em um instinto, essa passagem da ideia ao fisiológico e seu caminho inverso. Seria a psicologia que estudaria a vontade, não mais com o apelo idealista ou metafísico que esse conceito tinha, nem mesmo como vontade de representação, mas como "vontade de poder", isto é, vontade de criação de valores e de sentido.

Na mesma direção da crítica à "vontade de verdade" da psicologia de sua época, Nietzsche (ABM, §12) questionaria também os valores alcançados pretensamente por meios científicos e que, em sua análise, não passariam de sentimentos morais. É importante destacar em Além do bem e do mal a presença da crítica acerca de uma pretensa partícula indivisível da realidade, proposta pelo atomismo materialista. Sua posição contra o atomismo materialista se constrói como uma crítica à busca pelo imutável e o indivisível nos elementos mais microscópicos da realidade. Tal empreitada à procura da 
partícula indivisível da matéria, do ponto de vista do filósofo, seria uma expressão da vontade metafísica dentro da ciência. Esse diagnóstico do grande psicólogo se estenderá para o estudo da alma: ao lado do "atomismo materialista", haveria também um “atomismo anímico”. Qual seria, então, a partícula indivisível da alma para a psicologia que emerge na modernidade e a qual a "grande psicologia" nietzschiana se oporia? Qual seria o elemento dado, o eixo fixo de valoração do mundo tido como absoluto e imutável?

O "eu” e a "consciência” não seriam só valores dados como absolutos e causas primeiras da existência e da psique ("Penso, logo existo"), mas, dentro da tradição da filosofia moderna europeia, de Descartes a Schopenhauer, passando por Kant, seriam essas as estruturas capazes de tentar extrair a verdade do mundo (ABM, §54). Afinal, apenas um aparelho imutável, um eixo fixo, poderia fazer julgamentos verdadeiros e apreender valores e leis universais que constituem o mundo. Eixos móveis, estruturas mutáveis, não teriam parâmetros fixos de comparação para alcançar conclusões verdadeiras e objetivas do mundo.

Nesse sentido, a crítica nietzschiana se estende à psicologia para, justamente, trabalhar a partir de uma "grande psicologia" a concepção das forças e a vontade de cada tipo, de cada espécie, de cada fisiologia. Em sua crítica à psicologia da época, Nietzsche vai propor, precisamente, a genealogia desse aparelho psíquico dado como elementar e indivisível, a saber, a consciência. Para o autor (GC, §11 e §354), a consciência não passaria de um órgão do corpo, um órgão recentemente desenvolvido na história da evolução da existência, formando uma das especificidades do tipo de existência humana, e ainda bastante debilitado. No lugar da mente, da alma ou da consciência, dentro da análise psicológica e genealógica de Nietzsche, o corpo e a fisiologia, isto é, a organização e hierarquização dos impulsos de vida, seriam os principais objetos de estudo e fontes dos sistemas de pensamento, dos sistemas morais e dos modos de existência. Impulsionados pela "vontade de poder", seus sintomas expressariam o desenrolar e o câmbio desta vontade, inclusive, sua transformação numa vontade adoecida que negaria a própria existência.

\section{"Fisio-psicologia" e "inferência retroativa"}

Buscando suporte nas discussões eliciadas nos escritos nietzschianos sobre o musicista Wagner (CW, Epílogo), pode-se dizer que o modo de avaliação e interpretação, sejam de um indivíduo, de um povo ou de uma cultura, constituem modos de ser inconscientes. Tais modos de ser, sendo inconscientes, não poderiam ser desfeitos e 
desmanchados de maneira racional. A "grande psicologia", essa que estuda a vontade em sua complexidade além do embuste da consciência e do "eu”, seria, portanto, um estudo de uma dimensão inconsciente da vontade e do espírito. Complementando essa indicação, para Nietzsche, entender e pesquisar essas formas de avaliar e interpretar nada mais seria que uma compreensão da fisiologia aplicada (GC, §370). Daí o ponto fundamental não só da vida como "vontade de poder" e criação, mas também da crítica a partir do corpo na cosmovisão do filósofo. $\mathrm{O}$ corpo seria esse conjunto de forças que avaliaria e interpretaria, já não existiria alma como unidade indivisível (CW, No que faço objeções). A alma, a consciência, a razão, seriam todos órgãos desse corpo que corresponderia à "grande Razão" e que seguiria a vontade de poder e afirmar: sempre efeito da relação entre quantidades de força.

O genealogista, num golpe de ironia e alegria, usa da "pequena razão" para propor uma história do pensamento racional derivada da "grande razão" e do corpo. Para o psicólogo genealogista, a história da racionalidade, dos acontecimentos e dos valores se inscreveria nos corpos, no fisiológico, sempre como efeito, jamais como causa. $\mathrm{O}$ corpo seria a superfície de inscrição dos acontecimentos avaliados e interpretados pela moral e pelos costumes dos povos e indivíduos. O genealógico como proveniência se encontraria no ponto de articulação do corpo com a história, no sentido em que uma forma de julgar e uma perspectiva se engendram nos corpos ao longo do tempo e são ali naturalizados. Entretanto, o que é fisiológico em Nietzsche, e que por muitas vezes ele chama de instintivo, nunca seria um "já-dado" orgânico e individual, nunca se trataria de uma maneira de se absorver a realidade, mas sim, uma perspectiva, uma forma de produzir o real e a maneira como essa produção do real retroalimenta a formação deste organismo, deste nível fisiológico, de maneira complexa.

É importante frisar que, muitas vezes, o termo "fisiologia" em Nietzsche tem um sentido mais amplo, e muitas vezes oposto do que o sentido atribuído pela concepção da fisiologia experimental e orgânica desenvolvida a partir de meados do século XIX na Europa. Fisiologia, para o autor, ganha também um aspecto de tipologia e de psicologia, muito influenciado pelos filósofos e escritores franceses. Tal tipologia e psicologia estariam, sim, atreladas ao corpo, mas, não necessariamente à compreensão fisiológica e orgânica, que tenderia a um olhar objetivo dos órgãos e um equilíbrio do organismo como um todo, convencionada ao longo do século XIX.

A digestão e a visão, bem como os costumes e hábitos, valores e sentidos, seriam todas partes dos processos de produções corpóreos dentro do trabalho nietzschiano. Para 
a "grande psicologia" a "unidade subjetiva" passa a ser esse corpo histórico que, longe de ser unitário, trata-se mais de um campo de vetores de forças heterogêneas, de vontade múltiplas e conflitantes. A partir dessa ideia do embate de impulsos e afetos que compõem os corpos, Nietzsche (ABM, §19) levaria adiante a hipótese do corpo como uma "estrutura social de muitas almas". Assim, a consciência e a vontade do ego seriam serviços de comunicação dos vencedores de intensas batalhas no organismo, intensas disputas instituais. Dessa maneira, a compreensão da forma, da expressão e da estética produzida pelos corpos e pelos modos de ser, para Nietzsche, não passaria de físiologia aplicada (GC, §370).

Dentre os recursos de seu método análise psicológico e estético dos modos de ser a partir do nível fisiológico, Nietzsche destaca a ferramenta da "inferência retroativa". A inferência retroativa seria, segundo o próprio autor (GC, §370), uma das principais ferramentas que diferencia a psicologia desenvolvida pelo filósofo. A "inferência retroativa" seria a conclusão que se faz de um agente a partir de sua ação, da necessidade de sua ação. Por exemplo, quem teria a necessidade de escrever determinado livro? Quem teria determinada necessidade fisiológica de certa moral, de certos conjuntos de valores? Que fisiologia, com que determinadas configurações, necessitaria de tal o qual coisa? Que vontade criaria determinado modo de pensar, interpretar e valorar?

Inferir retroativamente seria pensar sobre que vontade precisa desta ação, quem faria disso algo instintivo? Em A gaia ciência (GC, §370), o autor aponta esse "como" sendo seu diferencial entre os psicólogos, diferencial esse que deixa sua visão aguçada para os problemas estéticos de sua época. No mesmo aforismo, Nietzsche traz a questão da fisiologia em relação à estética artística, tanto como espectador (aquele que responde fisiologicamente a assistir uma peça), quanto como criador (aquele que, instintivamente, necessita expressar-se de certa maneira). Seriam as vísceras do próprio Nietzsche que não mais suportariam a música Wagneriana, seria algo de instintivo no filósofo alemão que a rechaçaria. Ao mesmo tempo, seria um instinto decadente, uma vontade decadente, que amaldiçoa de certa forma a vida, que guiaria a criação wagneriana de acordo com a interpretação do filósofo.

Assim, conclui-se, tanto pela abrangência de seus exemplos, quanto pela quantidade de vezes que Nietzsche recorre a esta ferramenta em suas análises genealógicas sobre a cultura, movimentos religiosos e certos personagens históricos, que a "inferência retroativa" pode ser vista como algo mais do que um recurso para análise estética da produção artística. Quando Nietzsche aponta nesse texto que a estética seria 
fisiologia aplicada, pode-se concluir que o autor se refere à produção de quaisquer formas a partir da "grande razão", isto é, qualquer produção a partir da vontade de poder, a vontade de dominação dos impulsos que compõem os corpos. Assim, a inferência retroativa seria parte constituinte de sua "fisio-psicologia" capaz de avaliar o valor dos valores, seja de povos, indivíduos ou sistemas de pensamento, e compor assim o seu projeto genealógico.

É através dessa "fisio-psicologia", orientadora do método genealógico, que Nietzsche se debruçará sobre o problema da importância para a modernidade de ter o conceito alma como unidade indivisível e atrelada a valores metafísicos. Em consequência dessa predileção conceitual, a modernidade teria também eleito o "eu" e a "consciência" como unidades centralizadoras dessa alma indivisível. Os dois conceitos serão, portanto, também problematizados pela "grande psicologia".

\section{Uma psicologia livre de preconceitos morais metafísicos}

De acordo com o aforismo 23 de Além do bem e do mal, bem como com boa parte de todo o primeiro capítulo do livro, Nietzsche aponta que toda a psicologia, até então, teria estado presa a certos conceitos e temores morais, ou seja, se basearia em crenças e sensos comuns justificados de maneira pouco rigorosa e sem o devido aprofundamento racional. A força dos preconceitos morais metafísicos, ou seja, o preconceito da causalidade, da individualidade do sujeito, da indivisibilidade da alma, dos valores elevados do "eu", da consciência e da razão, do livre-arbítrio, do altruísmo, do melhoramento da humanidade, etc. teria conduzido até então a psicologia e a sua máinterpretação.

A psicologia que Nietzsche proporia, portanto, deveria ser livre dos preconceitos morais acima colocados. Para isso, a rainha das ciências seria baseada nos processos históricos de constituição disso que se convencionou chamar de alma e deveria compreender a relação desta parte do organismo com a relação entre a existência humana com o sofrimento, com a moral, com a produção histórica de valores e de sentidos que constituiu a humanidade como modo de ser. Portanto, a psicologia nietzschiana e sua compreensão do ser não poderia recorrer a um eixo fixo e moral, nem ao menos indicar a finalidade e o sentido derradeiro da existência, sendo todas essas características manifestações de moral metafísica e expressões de uma "vontade de verdade".

Seria, portanto, fundamental para a psicologia nietzschiana ver a alma como um processo histórico, melhor dizendo uma produção cultural de valores e interpretações que 
se entranharia nos corpos aprofundando a existência na forma do ser humano e produzindo nele uma alma. Para Nietzsche (ABM, §45) a alma tem uma história, uma história de emergência do corpo e de desenvolvimento, interiorização, aprofundamento, moralização e etc. Toda essa história estaria impregnada no modo de ser humano até os dias de hoje e faria com que se naturalizasse essa concepção de alma como uma estrutura indivisível, lar da vontade e da razão humana, essência do ser. Seria função da "grade psicologia”, portanto, fazer o estudo dos valores dos valores que aprofundaram a existência no formato do homem constituindo-o, e que teriam inventado historicamente e através da moral sua porção anímica, esse suposto eixo fixo que coordenaria nossas vivência para além do corpo físico e, até, para além do plano terrestre, como no caso de certas religiões e linhagens filosóficas.

Às compreensões do mundo que tomam o fixo e o imutável como parâmetro, ou que buscam uma determinação sobre as mudanças da existência, Nietzsche dará o nome de perspectivas moralizantes ou metafísicas. A psicologia que o filósofo propõe, portanto, tem o dever de se constituir livre dos preconceitos morais e da conceptualização metafísica. E, como vimos anteriormente seguindo as indicações do aforismo "Dos desprezadores do corpo", isto que a história do pensamento ocidental conheceu como alma, nada mais seria que uma das partes que constituiria o corpo, uma "parte-efeito", bem como a consciência (GC, §11) e o espírito. Trata-se, portanto, de um outro nome para uma função fisiológica.

\section{O problema da alma}

Assim, acompanhando o aforismo 12 de Além do bem e do mal, Nietzsche estende sua crítica ao atomismo materialista, a defesa da possibilidade de existência de uma partícula indivisível da matéria, até outra forma de atomismo, que ele dará o nome de atomismo anímico. Para o pensador, pensar na alma como uma estrutura unitária, individual e indivisível seria não apenas um erro que não se estenderia apenas à psicologia e a filosofia de sua época, mas que teria sua origem na moral religiosa que necessitava criar o homem em sua profundidade anímica e, dessa maneira, responsabilizar a existência por seus atos, inculcando e intrometendo nos corpos a responsabilidade pelas ações e a culpa.

Para além deste movimento crítico que avalia os valores e interpretações que apontam a alma e a vontade como elementos indivisíveis que inventam e fundamentam a forma humana, Nietzsche não despreza o conceito de alma, apontando-o como uma das 
hipóteses mais antigas e veneráveis (ABM, §12) e, além de colocar tal conceito na flecha do tempo da história e de suas mutações, sugere outra possibilidade para seu uso e compreensão. Seguindo ainda o aforismo 12 de Além do bem e do mal, Nietzsche aponta para possibilidade de que novos psicólogos passem a compreender e trabalhar com uma "alma mortal", "alma como pluralidade do sujeito" e "alma como estrutura social dos impulsos e afetos".

Desta maneira, no lugar de uma alma imortal e imutável, Nietzsche sugerirá uma alma que expressa o embate constante que seria o corpo, disputando e convivendo, como em uma estrutura social, inúmeros impulsos e afetos. Além disso, tal disputa que seria o corpo, seria uma peleja que aconteceria, em sua maior parte, fora do alcance do órgão da consciência (GC, §333, §354). Assim, temos como apanhado da compreensão nietzschiana de alma dentro de sua psicologia a compreensão da mesma como parte do corpo vivo, reflexo das necessidades fisiológicas (GC, Prefácio, §2); como uma estrutura múltipla e conflituosa (ABM, §12); como algo mortal dentro da linha do tempo da história e de suas mudanças, até mesmo sociais (ABM, §12, §45); finalmente, cuja maior parte da atividade se opera de maneira independente do órgão da consciência (GC, §333, §354).

Como já colocado acima, para Nietzsche, grande parte da atividade mental ocorreria fora do registro e do nível da consciência. Todo pensamento, toda impressão, toda vontade começaria a ser formado de maneira inconsciente, fisiológica, instintiva, e teria a finalidade de preservar determinado modo de vida (ABM, §3). Todo ser vivo quereria, em primeiro lugar, dar vazão à sua força e ganhar ainda mais potência justamente pela vida ser expressão da vontade de poder (ABM, §13). No caso do modo de ser humano, dotado de consciência, a vontade, bem como alma, seria descrita pelo filósofo do eterno retorno como algo múltiplo e derivado de um constante conflito, diferente do que o idealismo metafísico pregaria, isto é, alma como unidade e fundamento do ser humano como existência dada a priori.

Como trazido até aqui, dentro da tradição do pensamento moderno, seja este expresso através da filosofia, da religião ou da moral, essa alma individual e indivisível se confundiria com o "eu", lar do órgão da "consciência", como unidades de orientação da condução anímica. Com o objetivo de traçar a crítica da psicologia nietzschiana em direção ao aparelho da consciência, optou-se por recorrer adiante especialmente aos aforismos 11 e 354 de A gaia ciência para definir o aparelho da consciência como mais um órgão do corpo. Outros aforismos de Além do bem e do mal, Crepúsculo dos ídolos, Humano, demasiado humano e $O$ anticristo edificarão o argumento nietzschiano acerca 
da evolução histórica da consciência no âmbito gregário, comunicativo e gramatical.

\section{Consciência como órgão reflexivo}

A tarefa negativa da psicologia nietzschiana visaria demolir a concepção de que a consciência seria a estrutura fundante do espírito e da alma em ao menos três vias aqui apresentadas: a via da comunidade, da comunicação e da estrutura linguística. Essas vias alicerçam o preconceito moral da modernidade, até Nietzsche, em acreditar que a alma e toda a pluralidade de fenômenos psíquicos se identificariam exclusivamente com o aparelho da consciência. Esses mesmos pontos produzem a história de como um órgão posterior e debilitado como a consciência pode se formar e constituir o modo de ser do homem moderno baseado de maneira central na faculdade da razão.

No aforismo 354 de A gaia ciência, Nietzsche esboça a hipótese pertinente à soberania dos instintos e das pulsões sobre a consciência. Essa suposição se construirá através da exposição da história da gênese da consciência no animal humano. Dentro desse aforismo nomeado "Do 'gênio da espécie" pode-se encontrar ao menos três temas de crítica diante do problema da consciência ou de tornar-se consciente, a saber: a origem da consciência a partir do próprio organismo; a consciência como necessidade de socialização e comunicação; e, por fim, a indissociabilidade da consciência de uma malha gramatical limitadora. Exporemos aqui cada um desses temas a fim de, não só criticar a premissa de que a consciência e o " $e u$ " seriam os elementos ao redor do qual a alma se organizaria, mas também como maneira de acesso à perspectiva psicológica profunda, isto é, inconsciente, de Nietzsche.

A consciência teria uma genealogia orgânica, e não divina, e a "grande psicologia" desenharia essa trajetória acinzentada (GC, §11 e GM, Prefácio, §7). De fato, para Nietzsche, a consciência seria o último recurso, o último órgão a se desenvolver em nosso organismo e, por isso, seria mais inacabado, menos forte e fruto de juízos e de avaliação do mundo e de nós que, sem a ligação intensa com a orientação dos instintos, nos levaria à morte, à impossibilidade de manter a vida diante das variações do mundo. A consciência seria ainda ingênua demais para dependermos dela a nossa sobrevivência. Na contramão da tradição filosófica ocidental, a psicologia de Nietzsche não só eliminaria a distinção hierárquica entre o racional e o sensível, como colocaria a razão e seu principal instrumento psíquico de execução - a consciência - a serviço do sensível, isto é, do corpo e de sua pluralidade de instintos, impulsos e afetos.

Em outras palavras, essa psicologia colocaria a mente e o aparelho da razão como 
partes do corpo, como parte do todo material, como parte de uma "grande razão" que seria o corpo (Z, I, Dos desprezadores do corpo). Seria o próprio afeto do orgulho que elevaria nossa consciência como o âmago do modo de ser humano, como sua derradeira identidade. Seria o orgulho instintual que a tiranizaria e garantiria sua existência e o nosso apreço por ela (GC, §11). O orgulho que tomaria a consciência como uma coisa dada e identificá-la-ia como unidade imutável de nosso organismo. Assim, essa compreensão, essa perspectiva que quer conservar esse novo órgão, negaria seu desenvolvimento, sua história, a memória de sua constituição recente e debilitada, suas fraquezas e intermitências. Dessa maneira tiranizada, os juízos autoritários da consciência, tida como monarca da alma, não passariam de erros, de avaliações deslocadas do corpo e da vida. A consciência que, com o tempo de sua utilização e aprimoramento, cumpriria o papel de transmutar o conhecimento em instinto (GM, II, §2), ainda não serviria a esse propósito.

Apontando os avanços nos estudos da fisiologia humana e animal, Nietzsche indica que o organismo seria capaz de pensar, sentir, querer e "agir" de maneira geral sem que isso dependesse ou sequer alcançasse à esfera da consciência (GC, §354). Para o autor, a consciência nada mais seria do que um aparelho, um órgão reflexivo do organismo. Um sistema de impulsos que permitiria que saibamos que sabemos que estamos fazendo algo. Não só seria possível que vivêssemos sem esse espelhamento de todas as ações da vida como, na perspectiva do próprio Nietzsche, grande parte dos processos corporais, de fato, a maior parte de nossas vidas, já ocorreria sem esse espelhamento. Mais do que isso, grande parte de nossas experiências e vivências, não seriam nem mesmo acessíveis ao plano do órgão da consciência.

Tendo em vista a última afirmação de que grande parte de nossa vida pulsional não seria acessível à consciência (GC, §354), temos mais uma vez a temática da organização de uma atividade inconsciente em Nietzsche. Grosso modo, um conjunto de forças atuaria em nós independente de nosso conhecimento consciente delas, logo, seriam independentes de uma vontade unitária e conhecida (ABM, §17). O corpo seria um espaço composto por forças pulsionais, afetivas, instintuais, passionais, etc. (ABM, §19). O que nos alcançaria à consciência como vontade seria, em realidade, o resultado do embate das quantidades dessas forças. São essas mesmas forças biológicas, sociais, físicas, etc. que impulsionariam a formação do aparelho psíquico e da consciência organizada. A consciência seria um a posteriori, um resumo, um epílogo de nossa atividade pulsional. A imagem do resultado de um embate; o terminal de uma disputa de várias forças.

O genealogista poderia se perguntar, então: quem precisaria saber o que faz? Que 
tipo de espécie teria essa necessidade? Quem teria a necessidade de compreender a ação das forças que atuam e constituem o corpo de forma reflexiva? Quem teria essa necessidade seria aquele animal que precisa, de forma extrema, se comunicar, fazer-se entender, esforçar-se em transmitir aquilo que sente, aquilo que fez, faz e fará. Seria necessário um animal extremamente dependente e gregário para empurrar os instintos em direção a tal mecanismo de autorreflexão e, logo, de comunicação. A consciência seria um órgão de tornar a experiência comum, um órgão de comunicação. Desta maneira, a consciência seria esse aparelho que permitiria que o homem se tornasse, dentre todas as outras espécies, esse animal capaz de fazer promessas (GM, II, §1).

\section{Consciência e comunidade}

A capacidade da consciência de articular e apreender fixidez em um mundo de pura mudança, na leitura do grande psicólogo, estaria estritamente ligada à necessidade de se comunicar. Seria aí, no campo da comunicação, que residiria a força e a sutileza da consciência. Seria da fraqueza, da fragilidade, da necessidade do corpo do animal humano que derivaria a arte de se fazer entendido, de ter sua experiência individual expressada e, portanto, parte de suas necessidades compreendidas. (GC, §354). Isto não quer dizer que a comunicação não aconteceria entre os outros níveis de organização da vida na Terra (plantas e demais animais). No entanto, o avançado nível de comunicação que a consciência permite, o comunicar abstratamente a própria experiência, o saber que se sabe de algo, o poder de comunicar até mesmo a comunicação de outrem ou de outro fenômeno para outros, isso seria da alçada da nossa necessidade humana de criar planos comuns.

A consciência de si mesmo, a capacidade de entender para si e resumir aquilo que se sente e, assim, transmitir isso, essa dupla emergência da linguagem e da comunicação, se daria por um fator de fragilidade da existência na forma humana e necessidade de socialização. $\mathrm{O}$ animal que precisa tornar comum seus processos interiores, o animal que tem necessidade de comunicar seus próprios estados, intenções, motivos e pensamentos, seria o animal que precisaria de outros da mesma espécie para realizar suas tarefas, para sobreviver em meio às flutuações da vida. Nietzsche (GC, §354) pontua que um animal independente e, por exemplo, caçador solitário, não teria necessidade de comunicar seus processos internos e, portanto, se desenvolveria de maneira independente de um sistema avançado de comunicação com os outros de sua espécie. O humano como animal que, desde o nascimento, se apresentaria frágil e gregário, teria sido aquele que mais necessitou de comunicar suas vontades, necessidades, e demais processos internos aos pares de sua 
própria espécie.

Seja para ajudar uns aos outros, para proteger, para alcançar demandas individuais de forma coletiva, a nossa capacidade de comunicação nos conectaria através da consciência. Saber aquilo que sentimos, saber sobre aquilo que pensamos, saber sobre aquilo que queremos, nos serviu, na pré-história da consciência, pois necessitávamos dessa rede de proteção, dessa relação de mando e obediência entre nossos semelhantes. Nietzsche aponta ainda o funcionamento constante do pensamento, seja na criatura humana, seja em toda criatura viva, e que, desse fluxo contínuo de pensamentos e apreensões dos signos do mundo, apenas a menor parte nos é sabida, ou seja, apenas a menor parte se tornaria consciente (GC, §354).

\section{Consciência e comunicação}

De fato, as partes de nossos processos corporais que se tornariam conscientes seriam apenas aquelas que temos a necessidade e a capacidade de comunicar. A compilação de signos que podemos transformar em signos de comunicação, transformar em palavras para descrevermos o que sentimos, pensamos e fazemos. Ou seja, a parte de nossa experiência que, já reduzida e resumida ao entrar na consciência, se abrevia e se comprime uma vez mais para se tornar compreensível e comum ao acervo linguístico e comunicativo dos outros (GC, §354; ABM, §17). Seguindo essa suposição nietzschiana, seria correto afirmar que o animal humano também se faria entender, se comunicaria através de gestos, olhares, reações, etc.

$\mathrm{O}$ que chegaria à consciência seria, então, sempre médio. $\mathrm{O}$ meio termo entre aquilo que $e u$ posso expressar e aquilo que outros poderão entender. A consciência, para Nietzsche (GC, §354), não é uma parte fundamental da existência individual, mas uma parte que se desenvolve em função do gregarismo, da necessidade de formar rebanho e, assim, partilhar valores e sentidos. A consciência não nos traria aquilo que é individual e extremamente singular na experiência, nas vivências e na perspectiva de cada ser da espécie.

Mesmo quando nos esforçamos em galgar os degraus de um autoconhecimento, esse entendimento de si, quando realizado através da consciência, aconteceria preso ao que em nós é médio, comum, ordinário e vulgar. Suplantando o que há de singular em nós, cada uma de nossas ações, em função do comum, do médio, do coletivamente inteligível, a consciência nos carregaria para um plano gregário, um plano onde valores, sentidos e signos precisam manter-se comuns. Assim sendo, Nietzsche chega a alertar 
para os riscos da consciência como um órgão que pode hipertrofiar e gerar corpos adoecidos, isto é, corpos que não conseguem mais avaliar a e interpretar a partir de seus próprios instintos, mas apenas do gregarismo e em função do rebanho ao qual o animal humano pode pertencer (GC, §354).

Sendo o animal humano tão habituado à consciência e sendo essa consciência estritamente vinculada à linguagem e à comunicação de signos, as palavras ganham suma importância na existência do modo de ser humano, no seu modo de atribuir valores e sentidos. Seguindo a média exigida em toda comunicação, teríamos as palavras como um já dado, como um campo do comum, um campo da identificação e representação dos vários corpos do mundo. O que a psicologia nietzschiana teria feito seria separar abruptamente a realidade dessa dimensão comunicacional da palavra. Falar, comunicar, nomear seria apenas uma forma de avaliar e interpretar. Os corpos ganham nomes, valores e sentidos com a força com que as palavras lhes são impressas coletivamente.

Prosseguindo, sendo que grande parte da nossa realidade interna e externa seria avaliada e interpretada a partir da consciência e, consequentemente da linguagem e das palavras, tais valores e sentidos estariam limitados pela malha gramatical que rege uma linguagem. Nietzsche coloca a gramática, o conjunto de regras históricas de uma linguagem, como um importante ponto de análise a respeito da maneira como a consciência avalia e interpreta o mundo, bem como, consequentemente, essa mesma consciência tende a perpetuar erros de julgamento baseados em preconceitos morais metafísicos. A malha gramatical é o terceiro tema de crítica quanto à nossa capacidade auto reflexiva da consciência.

\section{Malha gramatical e os limites da consciência}

A malha gramatical se configuraria como expressão de uma vontade, um conjunto de forças que pressiona e compõe a estrutura lógica que organiza os signos e as palavras com as quais nos comunicamos. Tal estrutura lógica de organização não constituiria apenas regras de linguagem, mas constituiria modos de ser e de perspectivar o mundo provindos de indivíduos ou povos. Os limites gramaticais de uma linguagem constituiriam a expressão de nossos hábitos e preconceitos lógicos. Diferentes tradições filosóficas, provindas de diferentes lugares, Nietzsche (ABM, §20) cita os exemplos das filosofias indiana, grega e alemã, criam imagens do pensamento semelhantes umas às outras em função da similaridade gramatical de suas raízes linguísticas.

Essa seria a teoria linguística de Nietzsche, aproximando a linguagem da história 
e da política e destrinchando a função da mesma no nosso modo de ser. Nietzsche chama a gramática de metafísica do povo pois essa impõe valores absolutos ao pensamento (GC, §35). As noções de agente e de causalidade através das quais a gramática nos pressiona, nos força a pensar, proviriam de uma perspectiva de mundo demasiadamente ligada à metafísica, à substancialidade e à imutabilidade tanto dos objetos quanto dos agentes. A indivisibilidade do sujeito centrada no " $e u$ " e na vontade unitária, a perspectiva de que o mundo seria permanência e imutabilidade, de que haveria uma essência em cada uma das coisas em si e a desconexão causal, a falta de motivo e finalidade naquilo que causa no mundo, são exemplos do conjunto de noções e preconceitos metafísicos que a gramática pode anexar ao pensar (ABM, §17).

Os hábitos gramaticais e seus preconceitos metafísicos seriam capazes de, por exemplo, exigir um agente para cada uma das ações, de forma que pareceria impossível, por exemplo, pensar o próprio pensamento sem um agente, ou ainda, sem o "eu". O trabalho de Descartes não seria o de duvidar da gramática e do "eu" que pensa. A dúvida hiperbólica cartesiana apenas confirmaria a força da gramática e de seu preconceito quando não questionada (ABM, §54). Para Nietzsche (ABM, §20), posicionar-se de maneira genealógica diante da consciência, avaliar o valor da própria consciência, requereria avaliar o valor da gramática e a historicidade dessa composição de valores. A gramática insistiria que a vontade se passasse por unívoca, livre e conectada à unidade pronta do sujeito, conectada ao " $e u$ ". $E$ e penso, eu quero, eu sinto.

Entretanto, a vontade seria, para Nietzsche, a expressão de várias forças, como já dissemos, uma multiplicidade que se encontra, digladia e compõe os corpos. Batalha essa cujo resumo a consciência se esforçaria em captar (CI, Incursões de um extemporâneo, §26). O resultado de algo que pensa em mim, de um algo que age em mim (ABM, §17). A gramática pressupõe que existiria um agente individual para desencadear cada ação, como se agente e ação fossem coisas independentemente conectadas por certa intenção. É esse um dos preconceitos linguísticos que, segundo Nietzsche, nos enclausuram na estrutura fundante do " $e u$ " e da consciência. Ao dispensar o preconceito gramatical da dependência de um sujeito da ação e livrar sua gramática da indispensabilidade do "eu" para a ação, Nietzsche (ABM, §17) afirma que "isso" pensa, sente e quer como um processo, não como um agente. Mesmo esse “isso", esse algo indeterminado, já seria a intepretação de um processo, já seria algo dentro do campo da descrição (ABM, §17). Como colocado acima, não se sabe de nós e de nossas vontades através disso que seria mediano, ou seja, da consciência e da linguagem. 
Nietzsche disserta sobre a evolução e as consequências de nossos hábitos e preconceitos gramaticais e lógicos, presentes no modo de ser humano, bem como no nosso modo de avaliar e de interpretar a própria existência humana (HH, §39). Inicialmente, uma ação é avaliada como "boa" ou " $m a$ " independente de seu motivo, mas baseada em seu efeito, que pode ser útil ou prejudicial para esse que avalia. Logo, um efeito é avaliado. Em seguida, por um hábito gramatical, passamos a acreditar que essa qualidade seria inerente à $a c ̧ a \tilde{o}$, inerente à essência da ação. Dessa forma, as ações em si passam a ser interpretadas como boas ou más.

Da mesma maneira, a língua (ou sua dimensão comunicacional) faria designar características valorativas aos objetos em si, de forma que a pedra seria dura ou a árvore seria verde, apreendendo, dessa maneira, o efeito como causa. Nessa etapa da evolução da lógica gramatical e da avaliação, a ação é alvo do juízo. Adiante, passasse a avaliar os motivos e as intenções que levaram a determinada ação como bons ou maus, como se na ponta de cada ação houvesse uma vontade unívoca que a causasse. Nesse processo, a lógica gramatical leva o juízo de quem avalia a transferir a responsabilidade da ação inicial, avaliando o caráter do objeto ou do modo de ser humano de qual emana tal motivo.

Assim, a fonte do motivo é avaliada, e a suposta vontade do agente é responsabilizada. A existência na forma humana, como exemplo, torna-se, então, responsável pelo efeito de seus atos, de suas ações, de seus próprios motivos e de seu próprio ser. Em contrapartida a esta lógica causal imposta por vários anos pela gramática, Nietzsche (CI, Os quatro grandes erros, §7 e §8) argumenta que o homem seria a consequência necessária dos influxos de seu passado e seu presente e não poderia ser tomado como responsável por nada, pontuando assim a "irresponsabilidade" como conceito crucial de sua perspectiva de mundo. Estaria nesse conjunto de preconceitos morais e gramaticais uma das gêneses do erro da responsabilidade e da vontade-livre para o pensador.

O erro da vontade-livre incitaria a pensar que somos livres para decidir todas as nossas ações, quando, na interpretação nietzschiana, seríamos completamente irresponsáveis por nossas ações ${ }^{3}$, mas, mesmo assim, não poderíamos fugir de suas consequências. O ponto em debate remete uma vez mais à perspectiva de Nietzsche contrária a um centro unívoco da subjetividade, responsável pela motivação e a vontade dentro do modo humano como um todo, como "causa do mundo". Em sua visão da alma, historicamente construída e fragmentada em impulsos e afetos múltiplos, o efeito das ações que recai sobre os corpos não poderia ser julgado ou interpretado como algo 
linearmente causal. Refuta-se, assim, o entendimento moderno baseado na consciência que coloca na mesma linha de causalidade sujeito-intenção-ação.

Por fim, vale salientar, ainda usando como referência o aforismo 39 de Humano, demasiado humano, que Nietzsche aponta Schopenhauer como um dos filósofos que se prendeu à gramática em favor da metafísica. Para Schopenhauer, uma vez que seria possível sentir arrependimento por uma ação, entende-se que há em nosso ser uma liberdade de escolha perdida. A vontade precederia a existência. Daí, Nietzsche infere o erro lógico de Schopenhauer em duas vias.

Inicialmente, aponta o erro lógico da causa inferida do efeito (vontade e ser), em seguida, o afeto do remorso, do arrependimento, este só existiria devido à essa falsa percepção de que se é livre para escolher como agir, de que a existência humana possui essa característica do livre-arbítrio. O ressentimento e o remorso, combatidos por Nietzsche ao longo de sua obra como sintomas de adoecimento e decadência, proviriam da perspectiva de que poder-se-ia ter feito algo diferente, algo diferente poderia ter sido escolhido. Sobre o argumento de Schopenhauer de que existe uma conexão entre as ações e o ser do homem, ou seja, que haveria uma responsabilidade chamada vontade livre entre o ser e a ação, provada através do sentimento de culpabilidade que se sente por determinadas atitudes tomadas, Nietzsche $(\mathrm{EH}$, Por que escrevo tão bons livros, $\mathrm{O}$ nascimento da tragédia, §2) expõe que, em uma mesma cultura diferentes indivíduos pesam diferentemente ações semelhantes, alguns deles nem ao menos sentindo culpa ou remorso por certos movimentos que o fariam em outros indivíduos.

E que, de cultura para cultura, de momento histórico para momento histórico, haveria uma variação do conjunto de valores colocados que não garantiria sempre a mesma sensação de culpa em detrimento de ações específicas. Dessa forma, pode-se imaginar a suposição de que a nossa tradição gramatical que atribui valores de efeito às causas é uma das formas de se arraigar valores à consciência. Ou seja, em uma leitura, ao mesmo tempo, política e gramatical da consciência, Nietzsche, através de sua psicologia e de seu método genealógico, aponta nossa cultura e o conjunto de valores que a constitui como uma possibilidade, um modo de ser, e, ainda por cima, algo mutável. A cultura da gramática e da consciência que acreditam no livre-arbítrio do homem, na vontade livre e, portanto, tendem a confundir o ser do homem com suas ações, tenderia a responsabilizar o homem e a sua consciência por suas ações. Tal movimento moral será um importante elemento de organizações das forças reativas do ressentimento, da má consciência e do ideal ascético por parte dos sacerdotes em direção ao seu rebanho a constituição de nossa 
cultura (CI, Os quatro grandes erros, §7).

\section{Conclusão}

Concluímos, então, que Nietzsche se destaca como psicólogo, rompendo com certa tradição moderna de compreensão da própria Psicologia. Dentre os motivos que se destacam para que apontemos este rompimento está seu trabalho acerca da concepção histórica da constituição da alma e do aprofundamento do modo de ser humano, a partir de suas pulsões e afetos em contexto da vida social e gregária. Configura também como rompimento com a psicologia moderna o descentramento do aparelho da consciência e do "eu" da configuração anímica humana. Além disso, a psicologia de Nietzsche, sua "grande psicologia" constituiria parte essencial de seu método de análise genealógico e buscaria operar de maneira livre dos preconceitos morais metafísicos. Dessa maneira, alinhada como o processo genealógico de estudo das metamorfoses da vontade de poder em todos os campos de conhecimento (produção de valor e sentido), a psicologia tal como Nietzsche à perspectiva, ressaltaria seu estatuto de "rainha das ciências".

Como exemplo do funcionamento da psicologia de Nietzsche em relação ao seu método genealógico de análise, apresentou-se, brevemente, tanto o caso da genealogia da constituição da concepção moderna de alma como unidade indivisível do ser, apontada pelo autor como "atomismo anímico", bem como a análise dos fatores de constituição do aparelho da consciência. A respeito deste segundo caso, pode-se listar como fatores a estreita relação do animal humano com a vida em comunidade, a sua necessidade de comunicação e o envolvimento da consciência e sua maneira de apreender a realidade a partir de uma malha gramatical específica e limitante.

Tanto a concepção moderna da alma como estrutura unívoca, quanto a concepção da consciência como órgão capaz de dizer da totalidade e da vontade, seriam interpretados por Nietzsche e sua psicologia como instrumentos para produzir o homem como ser do ressentimento e da culpa. Tais recursos conceituais seriam lidos por Nietzsche como fatores históricos de controle sacerdotal, como expressões do ideal ascético e da sua disseminação do ressentimento em favor do controle do modo de existência humano fundamentado pelo instinto de rebanho. A "grande psicologia" de Nietzsche auxiliaria e visaria, como o restante de suas conclusões e ferramentas conceituais, a superação do modo de existência humano.

\section{Referências}


GIACOIA JÚNIOR, Oswaldo. Nietzsche como psicólogo. São Leopoldo: Ed. UNISINOS, 2001.

NIETZSCHE, Friedrich Wilhelm. Além do bem e do mal: preludio a uma filosofia do futuro. São Paulo: Companhia das Letras, 1992.

NIETZSCHE, Friedrich Wilhelm. A genealogia da moral. São Paulo: Companhia das Letras, 2013.

NIETZSCHE, Friedrich Wilhelm. Assim falou Zaratustra: um livro para todos e para ninguém. São Paulo: Companhia das Letras, 2011

NIETZSCHE, Friedrich Wilhelm. Crepúsculo dos ídolos: ou como se filosofa com o martelo. São Paulo, SP: Companhia das Letras, 2008

NIETZSCHE, Friedrich Wilhelm. Gaia Ciência, A. São Paulo: Companhia das Letras, 2012.

NIETZSCHE, Friedrich Wilhelm. Humano, demasiado humano. São Paulo: Companhia das Letras, 2001.

NIETZSCHE, Friedrich Wilhelm. O anticristo: maldição ao cristianismo; Ditirambos de Dionísio. São Paulo, SP: Companhia das Letras, 2007.

NIETZSCHE, Friedrich Wilhelm. O Caso Wagner: um problema para músicos; Nietzsche contra Wagner: dossiê de um psicólogo. São Paulo: Companhia das Letras, 1999.

Yan Menezes Oliveira

Universidade Federal do Espírito Santo

E-mail: yan_menezes@hotmail.com

Fabio Hebert da Silva

Universidade Federal do Espírito Santo

E-mail: fabiohebert@gmail.com

\footnotetext{
${ }^{1}$ Sobre o erro do livre arbítrio e a vontade livre em Descartes: AC, §14; em Schopenhauer: HH, $\S 39$ e ABM, $\S 19$.

2 "Isso" aparece como tradução da palavra "es" do alemão, pronome pessoal de terceira pessoa do singular atribuído a substantivos neutros.

${ }^{3} \mathrm{Um}$ agente independente não é a causa do mundo, porque esse mesma forma-agente também é efeito
} 